\title{
A PI3K Pathway Mediates Hair Cell Survival and Opposes Gentamicin Toxicity in Neonatal Rat Organ of Corti
}

\author{
Won-Ho Chung, ${ }^{1,2}$ Kwang Pak, ${ }^{1}$ Bo Lin, ${ }^{3}$ Nicholas Webster, ${ }^{3}$ and Allen F. Ryan ${ }^{1,4,5}$ \\ ${ }^{1}$ Department of Surgery Otolaryngology, UCSD School of Medicine and VA Medical Center, 9500 Gilman Drive \#0666, \\ La Jolla, CA, USA \\ ${ }^{2}$ Department of Otolaryngology and Head \& Neck Surgery, Samsung Medical Center Sungkyunkwan University School \\ of Medicine, 50 Ilwon Dong Kangnam Ku, Seoul, 135-710, South Korea \\ ${ }^{3}$ Department of Medicine, UCSD School of Medicine and VA Medical Center, 9500 Gilman Drive, La Jolla, CA \\ 92093-0666, USA \\ ${ }^{4}$ Department of Neurosciences, UCSD School of Medicine and VA Medical Center, 9500 Gilman Drive \#0666, La Jolla, USA \\ ${ }^{5}$ ENT-0666, UCSD School of Medicine, 9500 Gilman Drive, La Jolla, CA 92093-0666, USA
}

Received: 13 February 2006; Accepted: 27 July 2006; Online publication: 20 October 2006

\begin{abstract}
Gentamicin is well known to promote hair cell death in inner ear, but it also appears to activate opposing pathways that promote hair cell survival. In combination with others, our previous work has indicated that a K-Ras/Rac/JNK pathway is important for hair cell death and an H-Ras/Raf/MEK/Erk pathway is involved in promoting hair cell survival (Battaglia et al., Neuroscience 122(4):1025-1035, 2003). However, these data also suggested that a Ras-independent survival pathway for activation of MEK might be stimulated by gentamicin. To investigate alternatives to the Ras/Raf/MEK/Erk pathway in promoting hair cell survival, cochlear explants were exposed to gentamicin combined with several inhibitors of alternative pathways (LY294002, calphostin C, SH-6, U73122). When exposed to gentamicin with the PI3K inhibitor LY294002 $(10,50 \mu \mathrm{M})$, the protein kinase $\mathrm{C}(\mathrm{PKC})$ inhibitor calphostin $\mathrm{C}(50,100 \mathrm{nM})$ or the PKB/Akt inhibitor SH-6 $(5,10 \mu \mathrm{M})$, hair cell damage was significantly increased compared to gentamicin alone. By Western blotting, strong PKB/ Akt activation was observed in the organ of Corti following exposure to $50 \mu \mathrm{M}$ gentamicin for $6 \mathrm{~h}$. In
\end{abstract}

Correspondence to: Allen F. Ryan - ENT-0666 - UCSD School of Medicine 9500 Gilman Drive, La Jolla, CA 92093-0666, USA. Telephone: +1-858-5344594; fax: +1-858-5345319; email: afryan@ ucsd.edu addition, PKC activation by $12-O$-tetradecanoylphorbol-13-acetate protected outer hair cells from gentamicin induced cell death. In contrast, the phospholipase C- $\gamma$ (PLC $\gamma$ ) inhibitor U73122 (2, 5 $\mu \mathrm{M})$ did not affect hair cell damage when combined with gentamicin. Also, phosphorylation of PLC $\gamma$ was not increased in the organ of Corti following gentamicin treatment, as evaluated by Western blot. The results indicate that PI3K promotes hair cell survival via its downstream targets, PKC and PKB/ Akt. This suggests that both Ras-dependent and Rasindependent survival pathways are involved during gentamicin exposure. In contrast, PLC $\gamma$ activation of PKC does not appear to play a role.

Keywords: gentamicin, hair cell, ototoxicity, PI3K, PKC, PKB, Akt, PLC $\gamma$

\section{INTRODUCTION}

Gentamicin is well known to induce hearing loss and balance disturbance due to the ototoxic destruction of hair cells. Hair cell death due to gentamicin is thought to occur via a mixture of apoptosis and necrosis (Forge and Li 2000). The upstream events that lead to cell death are less clear. Recently, aminoglycosides have been reported to activate c-Jun-N-terminal kinase (JNK), and hair cell loss was 
prevented by the application of JNK inhibitors (Pirvola et al. 2000; Bodmer et al. 2002b; Ylikoski et al. 2002). Other recent evidence suggests that the intracellular signals leading to JNK activation in hair cells include the small $\mathrm{G}$ proteins Ras and Rac/cdc42 (Bodmer et al. 2002a). In particular, K-Ras may activate the pathway leading to JNK phosphorylation (Battaglia et al. 2003). Other pathways that promote cell death in ototoxicity have also been identified (e.g., Wu et al. 2002; McFadden et al. 2003).

In addition to pathways that promote hair cell death, gentamicin exposure also appears to activate opposing pathways that promote hair cell survival (Battaglia et al. 2003). This observation is consistent with current concepts of apoptosis regulation in cells, according to which cells are thought to exist in a finely tuned balance between survival and cell death (Raff 1992; Boatright and Salvesen 2003). Exposure of cells to stress disrupts this balance, and can activate opposing survival- and death-promoting pathways. If the stress is severe, apoptosis-promoting pathways tend to predominate and cell death results. This scheme suggests that intervention in apoptosispromoting pathways might prevent cell death, whereas intervention in survival-promoting pathways would enhance cell death.

We recently obtained evidence that activation of different isoforms of Ras may promote opposing outcomes in gentamicin-induced hair cell death in vitro. Treatment with low concentrations of the Ras inhibitor, FTI-277, sufficient to block the activation of $\mathrm{H}$ Ras, enhanced gentamicin-induced hair cell death, whereas concentrations that were high enough to block K-Ras protected hair cells (Battaglia et al. 2003). This observation is consistent with the activation of two signal transduction pathways in hair cells: an $\mathrm{H}$ Ras/Raf/MEK/Erk pathway promoting hair cell survival, and a K-Ras/Rac/JNK pathway leading to hair cell death. However, we also observed that the MEK inhibitor UO126 produced much stronger promotion of hair cell death than low-dose FTI-277. This suggested that a Ras-independent survival pathway for activation of MEK might be stimulated by gentamicin. One possibility for the alternative activation of MEK is phosphatidylinositol (PI) signaling.

Protein phosphorylation plays very important roles in various cellular physiologies. Protein kinase activity including protein kinase $\mathrm{C}$ has been demonstrated in normal organ of Corti (Coling and Schacht 1991). Also, aminoglycoside ototoxicity was shown to interact with PI metabolism (Schacht et al. 1977). Schacht and colleagues observed PI cascade abnormalities in hair cells during gentamicin ototoxicity, and further observed that aminoglycosides bind preferentially to phosphatidylinositol 4,5-biphosphate (PIP2). They also provided evidence that reactive oxygen species (ROS), products of oxygen metabolism by aminoglycosides, are responsible for their hair cell toxicity (Williams et al. 1987; Huang and Schacht 1990; Crann et al. 1992; Wu et al. 2002), and suggested that PI serves as an electron donor for ROS formation. PI may also participate in other ways, because in various tissues membrane inositol phospholipids are second messengers that serve as important components of signal transduction pathways (Nishizuka 1986).

PI signal transduction pathways include phospholipase C- $\gamma$ (PLC $\gamma)$, phosphatidylinositol 3-kinase (PI3K) and protein kinase C (PKC). PKC is a lipid activated serine/threonine kinase and has been known to have both antiapoptotic and proapoptotic functions depending on its isoforms (Webb et al. 2000; Bright and Mochly-Rosen 2005). Certain PKC isoforms can promote cell survival by directly phosphorylating Raf-1 without Ras activation and leading to activate Raf/MEK/Erk pathways (Kolch et al. 1993; Huang et al. 1995; McCubrey et al. 2000; Oliva et al. 2005). PKC isoforms can be activated by either PLC $\gamma$ or PI3K. For example, PLC $\gamma$ can be activated by the phosphorylation of tyrosine residues upon occupation of cell surface receptors by growth factors. The activated PLC $\gamma$ catalyzes the hydrolysis of PIP2 to generate diacylglycerol and inositol triphosphate (IP3). The former activates PKC isoforms and the latter stimulates the release of $\mathrm{Ca}^{2+}$ from internal stores (Nishizuka 1986; Oliva et al. 2005). The PI3K pathway is a well-known signal pathway activated by cellular stress (Cantley 2002; Franke et al. 2003). PI3K catalyzes phosphorylation of PI at the $3^{\prime}$ position of the inositol ring to convert the plasma membrane lipid PIP2 into phosphatidylinositol 3,4,5trisphosphate (PIP3). This molecule recruits protein kinase $\mathrm{B}$ (PKB, also called Akt) and phosphoinositide-dependent kinase 1 (PDK-1). PDK-1 phosphorylates and activates PKC isoforms (Huang et al. 1995; Balendran et al. 2000; Webb et al. 2000; Cantley 2002; Kuemmerle 2003; Bright and Mochly-Rosen 2005). Protein kinase B (Akt) is the common downstream target of PI3K. PDK-1 also phosphorylates and activates $\mathrm{PKB} / \mathrm{Akt}$, which is known to have several potential antiapoptotic functions including phosphorylation of Bad (Wang et al. 1998; Khwaja 1999; Song et al. 2005; Barthel and Klotz 2005). A schematic illustration of PI3K signaling is presented in Figure 8.

In the current study, we investigated alternatives to the Ras/Raf/MEK/Erk pathway in promoting hair cell survival when exposed to gentamicin. We present evidence that PI3K is involved in a hair cell survival pathway activated by gentamicin in vitro, but that PLC $\gamma$ is not. Our data also indicate that the PI3K 
downstream targets $\mathrm{PKB} /$ Akt and $\mathrm{PKC}$ promote hair cell survival.

\section{MATERIALS AND METHODS}

\section{Cochlear explant culture}

Explants of sensory epithelia were isolated from the basal turn of p5 Sprague-Dawley rat cochleas. Explants were maintained in Dulbecco's modified Eagle's medium (DMEM) with $10 \%$ fetal bovine serum (FBS) and $30 \mathrm{U} / \mathrm{ml}$ penicillin, to which HEPES buffer had been added to a concentration of $25 \mathrm{mM}$. Culture wells containing $500 \mu \mathrm{l}$ of medium in each were maintained in an incubator at $37^{\circ} \mathrm{C}$ with $5 \% \mathrm{CO}_{2}$ and $95 \%$ humidity.

For the gentamicin-alone condition, explants were maintained in the initial medium for 12-24 h, during which period they attached to the culture surface, and then exposed to medium containing 35 or 50 $\mu \mathrm{M}$, depending on the batch, of gentamicin (Sigma) for $48 \mathrm{~h}$. Gentamicin dose was adjusted to provide partial destruction of outer hair cells over two days. Primarily due to batch differences, and perhaps due to differences in rat litters, the degree of outer hair cell damage varied even with a single dose of gentamicin. Thus outer hair cell losses due to gentamicin alone varied around an average of $50 \%$. For this reason, a gentamicin-alone condition was included in each study performed, and was used as the control for that study. For inhibitor studies, cultures were first maintained overnight (12-24 h) with a medium containing the test inhibitors. They were then challenged with medium containing 35 or $50 \mu \mathrm{M}$ gentamicin plus the test inhibitors for an additional $48 \mathrm{~h}$. In addition, to evaluate the toxicity of inhibitor, explants were maintained for $72 \mathrm{~h}$ in medium containing inhibitor alone at the maximal concentration we used. After treatment, the explants were fixed and evaluated. The doses of test inhibitors employed were based on published $50 \%$ inhibitory concentrations $\left(\mathrm{IC}_{50}\right)$ in other whole-cell systems, so that the highest level used exceeded the $\mathrm{IC}_{50}$. The PKC inhibitor calphostin C (100, 50, $10 \mathrm{nM})$ (Sigma), the PI3K inhibitor LY $294002(50,10 \mu \mathrm{M})$ (Sigma), the PKB/Akt inhibitor SH-6 (10, $5 \mu \mathrm{M})$ (A.G. Scientific), and the PLC $\gamma$ inhibitor U73122 $(5,2 \mu \mathrm{M})$ (Sigma) were used. To activate $\mathrm{PKC}$, explants were exposed to $12-\mathrm{O}$-tetradecanoylphorbol-13-acetate (TPA; Sigma; 1, 10, 20, or $50 \mathrm{nM}$ ) overnight prior to, and simultaneously with, $35 \mu \mathrm{M}$ gentamicin exposure. For each condition, a minimum of six separate explants was used. All explants from an individual experimental day, typically 36-48 explants from 18 to 24 rat pups, were randomly distributed across conditions.
Evaluation and data analysis of inhibitor study

The explants were fixed with $4 \%$ paraformaldehyde for $30 \mathrm{~min}$ at room temperature, then treated with blocking solution containing 10\% FBS and 5\% Triton X-100 in phosphate-buffered saline (PBS). The explants were stained with a conjugated phalloidin-rhodamine probe in PBS for $60 \mathrm{~min}$ at room temperature. They were washed with PBS twice and visualized by fluorescence microscopy. Phalloidinrhodamine stains the F-actin of the stereocilia and cuticular plate of viable hair cells. To assess the suitability of this method, some gentamicin-treated explants were double-labeled with phalloidin and an antimyosin VIIA antibody. We observed excellent agreement between the two methods, indicating that we were not failing to detect hair cells with the phalloidin assay.

Hair cells were regarded as missing if no stereocilia or cuticular plate was observed in the appropriate location. Quantitative analysis was obtained by evaluating 30 outer hair cells associated with 10 inner hair cells in a given microscope field. Four microscope fields were counted for each explant, and these were averaged to obtain a value for that explant.

Statistical analysis was performed to compare hair cell number after treatment with gentamicin and with different inhibitors or TPA by using analysis of variance (ANOVA) followed by the least significant difference (LSD) post-hoc test with correction for repeated measures (Stat View 5.0). Differences associated with $P$ values of less than 0.05 were considered to be statistically significant. All data are presented as mean \pm SD.

\section{Western blotting}

Antibodies against the active form of signaling molecules were used to verify the activity state of signaling proteins following ototoxic exposure. Gentamicin-treated and normal control organ of Corti samples were used for Western blotting. Each sample consisted of the basal turn sensory epithelium from 20 p5 rat cochleas to obtain sufficient protein. Explants were exposed to $50 \mu \mathrm{M}$ gentamicin for $6 \mathrm{~h}$. Explants were collected from media, washed with icecold PBS, spun down (2000 rpm for $5 \mathrm{~min}$ ) and lysed with $100 \mu \mathrm{l}$ sodium dodecyl sulfate (SDS) phosphatase inactivation buffer $(50 \mathrm{mM}$ Tris, $\mathrm{pH} 6.8,10 \%$ glycerol, 2\% SDS, $0.005 \%$ bromophenol blue, 100 $\mathrm{mM}$ dithiothreitol, $1 \mathrm{mM}$ sodium fluoride, $1 \mathrm{mM}$ sodium orthovanadate, $1 \mathrm{mM}$ leupeptin, $1 \mathrm{mM}$ PMSF), boiled for $10 \mathrm{~min}$ to denature proteins and sonicated for 15 min to shear chromosomal DNA. Equal volumes $(30 \mu \mathrm{l})$ of these lysates were separated by SDS-polyacrylamide gel electrophoresis (PAGE) 
on $7.5 \%$ gels, and electrotransferred to polyvinylidene difluoride (PVDF) membranes (Immobilon-P; Millipore, Bedford, MA, USA). The membranes were blocked with $5 \%$ nonfat dried milk in TBS-Tween [50 mM Tris-HCL ( $\mathrm{pH}$ 7.4), $150 \mathrm{mM} \mathrm{NaCl,} 0.1 \%$ Tween 20] for $60 \mathrm{~min}$ at room temperature. Blots were incubated with primary antibodies in blocking buffer overnight at $4^{\circ} \mathrm{C}$ and then incubated with horseradish peroxidase-linked secondary antibodies followed by chemiluminescent detection. Antiphospho-AKT and antiphospho-PLC $\gamma$ antibodies (Cell Signaling) were used at a dilution of 1:1000. To verify protein loading, the PVDF membranes were immediately stripped by placing the membrane in stripping buffer $(0.5 \mathrm{M} \mathrm{NaCl}$ and $0.5 \mathrm{M}$ acetic acid) for $30 \mathrm{~min}$ at room temperature. The membrane was then washed once for $10 \mathrm{~min}$ in TBS-Tween, reblocked, and blotted with antibodies to an internal control protein ERK1 (total ERK, Cell Signaling). The intensities of the bands corresponding to phospho-AKT, phosphoPLC $\gamma$ were quantified by using an EDAS290 gel documentation system (Kodak, Rochester, NY, USA) with an Agfa Arcus II scanner. Band intensity for the phosphoproteins was corrected for intensity of our internal control signaling protein (total ERK) and then expressed as the percentage increase, compared with the nontreatment tissue. Each assay was performed three times. Antibody against phospho-PKC (Cell Signaling) was also employed but did not produce a signal in repeated attempts. Ratio data were analyzed using the Mann-Whitney nonparametric statistical test.

\section{RESULTS}

\section{In vitro toxicity of gentamicin}

Phalloidin-rhodamine stained normal control explants showed well-arrayed inner and outer hair cells after $72 \mathrm{~h}$ of culture. Basal turn equivalent explants cultured for $24 \mathrm{~h}$ and then treated with gentamicin for $48 \mathrm{~h}$ showed significantly reduced numbers of outer hair cell stereocilia and cuticular plates. The first row of outer hair cells exhibited the most damage, and damage to the third row was the least. The inner hair cells were more resistant to gentamicin than the outer hair cells (Fig. 1A, B).

PI3K, PKC, and PKB/Akt are involved in a hair cell survival pathway induced by gentamicin

Treatment of explants with the PI3K inhibitor LY 294002 (Sigma, $50 \mu \mathrm{M}$ ) alone did not damage cochlear hair cells. However, the combination of $50 \mu \mathrm{M}$ LY 294002 with gentamicin significantly worsened the degree of hair cell damage when
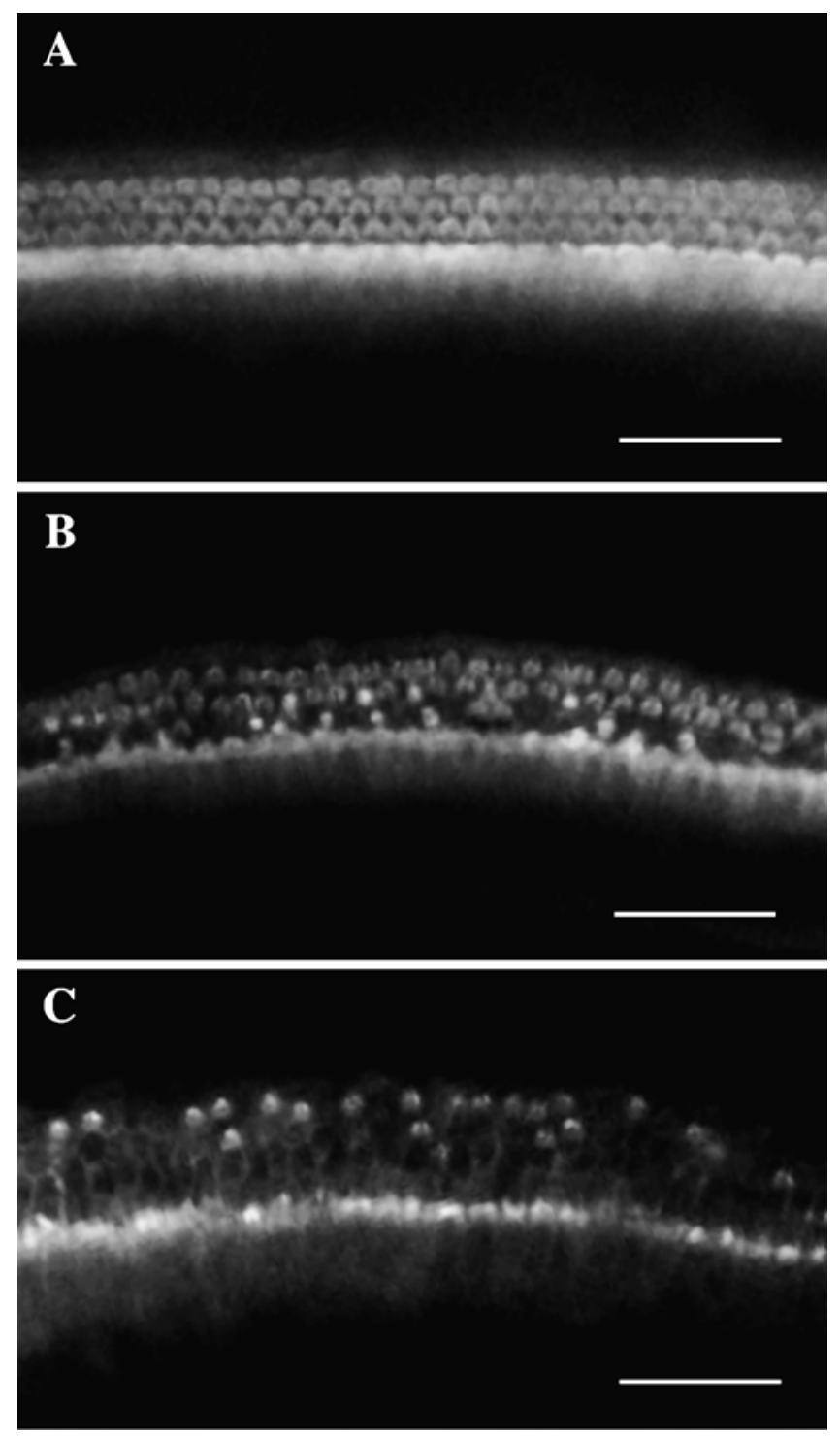

FIG. 1. Fluorescence microscopic images of phalloidin-stained organ of Corti explants: (A) normal control; (B) gentamicin $(35 \mu \mathrm{M})$ treatment; and $(\mathrm{C})$ gentamicin $(35 \mu \mathrm{M})$ treatment combined with the PKC inhibitor calphostin C (100 nM). In the normal control culture, one row of inner hair cells and three rows of outer hair cells are visible. In the gentamicin-treated explant, the outer hair cells are damaged, especially in the first row, whereas the inner hair cells are intact. The calphostin C- and gentamicin-treated culture exhibits the worse hair cell damage, with extensive loss from the second and third rows of outer hair cells.

compared to gentamicin alone. There was no effect on hair cell damage induced by gentamicin at a concentration of $10 \mu \mathrm{M}$ of LY 294002 (Fig. 2).

Treatment of explants with the PKC inhibitor calphostin C (Sigma, $100 \mathrm{nM}$ ) alone also did not induce damage of outer or inner hair cells. However, combined calphostin $\mathrm{C}$ and gentamicin exposure induced significantly more hair cell damage than was produced by gentamicin only at calphostin C con- 


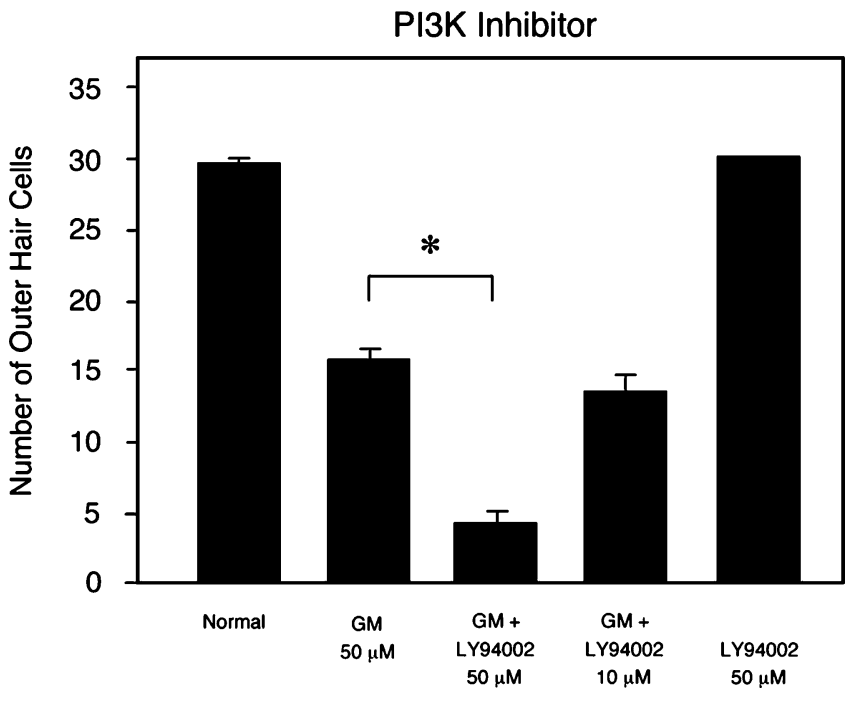

FIG. 2. Quantitative analysis of hair cell damage by gentamicin combined with the PI3K inhibitor, LY 294002. LY294002 significantly enhanced hair cell damage at a concentration of $50 \mu \mathrm{M}$ $(p<0.05)$, but not at $10 \mu \mathrm{M}$. LY294002 alone had no effect on hair cells.

centrations of 50 and $100 \mathrm{nM}$ (Figs. 1C and 3). At 10 $\mathrm{nM}$, there was no effect on gentamicin toxicity.

Treatment with SH-6, an inhibitor of $\mathrm{PKB} / \mathrm{Akt}$, combined with gentamicin significantly increase gentamicin toxicity at $10 \mu \mathrm{M}$ (Fig. 4). There was no effect on hair cell damage at $5 \mu \mathrm{M}$. Also, SH-6 alone $(10 \mu \mathrm{M})$ did not show any effect on hair cell survival.

The PKC activator TPA was shown to be protective against gentamicin-induced hair cell loss at concentrations of 5,10 , and $50 \mathrm{nM}$. Treatment of explants with TPA (50 nM) alone had no effect on hair cells (Fig. 5).

To determine whether phospho-Akt protein, downstream of PI3K pathway, is up-regulated in gentamcintreated tissue, Western blotting was performed. Using total Erk1 as an internal control, normalized phosphoAkt protein levels against Erk1 were expressed as \% of control. In three replicates, the relative intensity of phopho-Akt was increased over twofold in gentamicintreated tissue compared to tissue maintained in tissue culture media only (Fig. 6).

Hair cell survival pathway induced by gentamicin is not PLC $\gamma$-dependent

Treatment with the PLC inhibitor U73122 alone (5 $\mu \mathrm{M})$ had no effect on hair cell survival. When combined with gentamicin, U73122 $(5,2 \mu \mathrm{M})$ also had no significant effect on gentamicin-induced hair cell loss (Fig. 7). These concentrations equal or exceed those found to significantly reduce PLC $\gamma$-mediated responses in breast cancer cell (Katterle et al. 2004), rat pituitary cells (Leblanc et al. 1998), and neuroblastoma cells (Santagata et al. 2001). By Western blot,
phospho-PLC protein level normalized against total Erk1 was not increased in gentamicin-treated organ of Corti sample compared to normal controls (Fig. 6).

\section{DISCUSSION}

Gentamicin-induced damage to hair cells that we observed in culture is similar to that reported previously (Battaglia et al. 2003; Bodmer et al. 2002a). Moreover, the agreement we observed between phalloidin and MyoVIIa labeling suggests that we did not miss surviving "topless" hair cell somata in our assays. However, it should be noted that in vitro toxicity assessed in neonatal cultures may occur by different mechanisms than in vivo toxicity in adults. For example, it has been noted that high-dose aminoglycoside treatment in vitro can lead to rapid blebbing of the apical hair cell surface (Richardson and Russell 1991), not normally observed in vivo. We used relatively low gentamicin dosages that appear to mimic many features of adult, in vivo ototoxicity, including basal turn sensitivity, first row outer hair cell sensitivity followed by second and third row and then inner hair cells, cJun phosphorylation in hair cell nuclei, caspase 3 activation in hair cells, and hair cell loss over days. However, our data should be considered with the limitations of neonatal tissue and in vitro ototoxin exposure in mind. Also, it is possible that the intracellular events that underlie our results occur, not in hair cells, but in the supporting cells that make up a significant fraction of our cultures. As may also occur in vivo, any of our treatments could

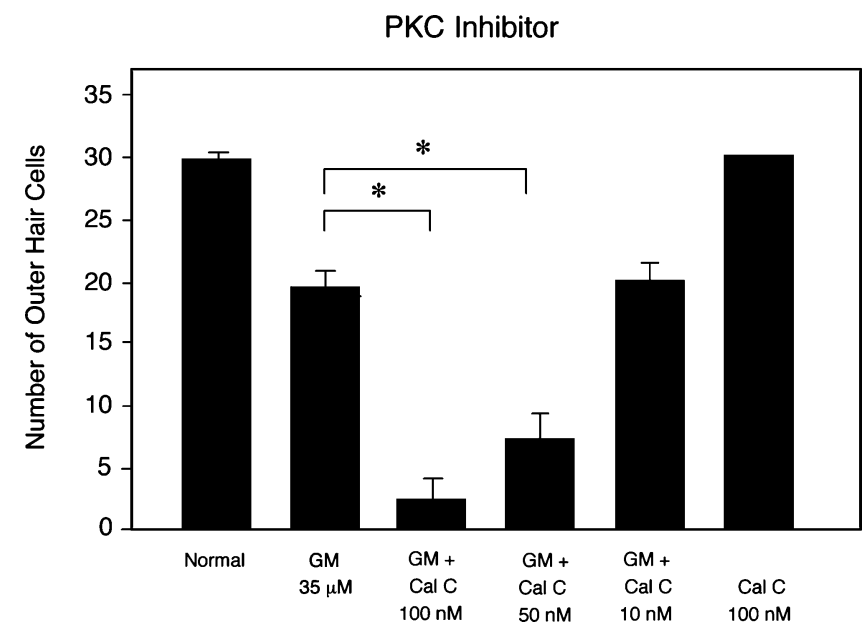

FIG. 3. Quantitative analysis of hair cell damage due to gentamicin combined with the PKC inhibitor, calphostin C. Gentamicin alone $(35 \mu \mathrm{M})$ induced outer hair cell damage of about $30 \%$. Calphostin $\mathrm{C}$ with gentamicin enhanced hair cell damage significantly at 50 and $100 \mathrm{nM}(p<0.05)$, but not at $10 \mathrm{nM}$. Calphostin C alone at $100 \mathrm{nM}$ had no effect on hair cells. 
PKB Inhibitor

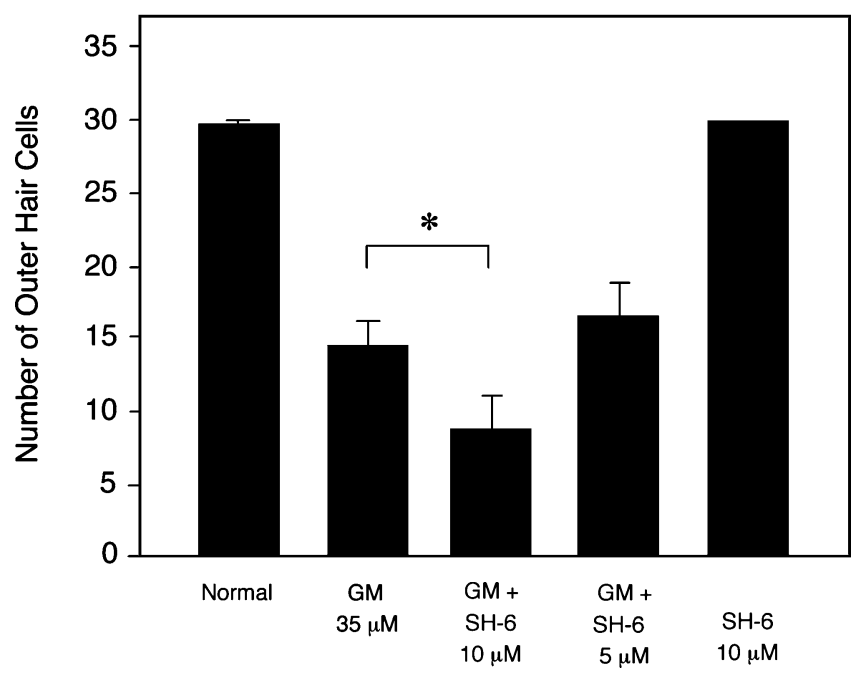

FIG. 4. Quantitative analysis of hair cell damage by gentamicin combined with the PKB inhibitor, $\mathrm{SH}-6$. When combined with gentamicin, $\mathrm{SH}-6$ enhanced hair cell damage at a concentration of $10 \mu \mathrm{M}(p<0.05)$, but not at $5 \mu \mathrm{M}$. SH-6 (at $10 \mu \mathrm{M})$ alone had no effect on hair cells.

have affected supporting cell-mediated survival promotion of hair cells.

We have previously shown that gentamicin activates a hair cell survival pathway via H-Ras dependent Raf1/MEK/Erk (Battaglia et al. 2003). However, our data suggested that MEK might also be activated in a Ras-independent manner. Results of the current study suggest an additional survival pathway involving PI3K, PKC, and protein kinase B (PKB/Akt).

PI3K is activated by a variety of growth and survival factor receptors including insulin, insulin-like growth factor (IGF-1) and cytokine receptors (Webb et al. 2000; Cantley 2002; Kuemmerle 2003; Barthel and Klotz 2005; Song et al. 2005). Activated PI3K phosphorylates membrane lipid PIP2 at the 3 '-OH position to generate PIP3. PIP3 recruits signaling proteins to the membrane, where they are activated. These include protein kinase B (PKB, also called Akt) and PDK-1. PDK-1 phosphorylates and activates PKB/ Akt (Rameh and Cantley 1999; Kuemmerle 2003). The activation of $\mathrm{PKB} / \mathrm{Akt}$ often mediates the transduction of cell survival signals (Rameh and Cantley 1999). In particular, PI3K activation of PKB/Akt has been shown to oppose cell injury and death in a variety of cell types (Barthel and Klotz 2005) including epithelial cells (Takeuchi and Ito 2004), myocytes (Fukazawa et al. 2003), and neuroblastoma cells (Emran et al. 2002).

PDK-1 also phosphorylates and activates other PI3K-dependent effectors including all of the many PKC isoenzymes (Webb et al. 2000; Cantley 2002; Kuemmerle 2003; Bright and Mochlly-Rosen 2005;
Oliva et al. 2005). However, there is an alternative pathway to activate PKC isoforms. Mitogenic signals that stimulate growth factor receptors can activate PLC $\gamma$. This is rapidly followed by tyrosine phosphorylation of PLC $\gamma$ and its dissociation from the receptor (Carpenter and Ji 1999). Activated PLC $\gamma$ hydrolyzes PIP2 into IP3 and diacylglycerol. IP3 mediates $\mathrm{Ca}^{2+}$ mobilization, and diacylglycerol (DAG) activates PKC. PKC can directly phosphorylate Raf-1 and increase its kinase activity without Ras activation (Kolch et al. 1993; Huang et al. 1995). Both PLC/ PKC and PI3K/PDK-1/PKC downstream signaling can involve the Raf-1/MEK/ERK MAPK cascade following growth factor stimulation (Cai et al. 1997; Schonwasser et al. 1998). In inner ear sensory epithelia, including avian epithelia and mammalian utricular macula, $\mathrm{PKC}$ is involved in cell proliferation (Montcouquiol and Corwin 2001; Witte et al. 2001).

These pathways provide multiple opportunities for intervention using well-established pharmacological inhibitors. For all inhibitors used, the concentration was based on the dosages that produce robust suppression of activity mediated by the factor in question in other cell types (Kobayashi et al. 1989; Ozaki et al. 1999; da Rocha et al. 2002; Montcouquiol and Corwin 2001; Vlahos et al. 1994; Brunn et al. 1996; Jin et al. 1994; Kozikowski et al. 2003). Unfortunately, no specific inhibitor of PDK1 is commercially available. For all inhibitors, we have tested for direct toxicity to hair cells and found them to cause no detectable damage at the maximum dosages we employed. Our data are based on in vitro experiments. However, it should be noted that in vivo studies would be needed

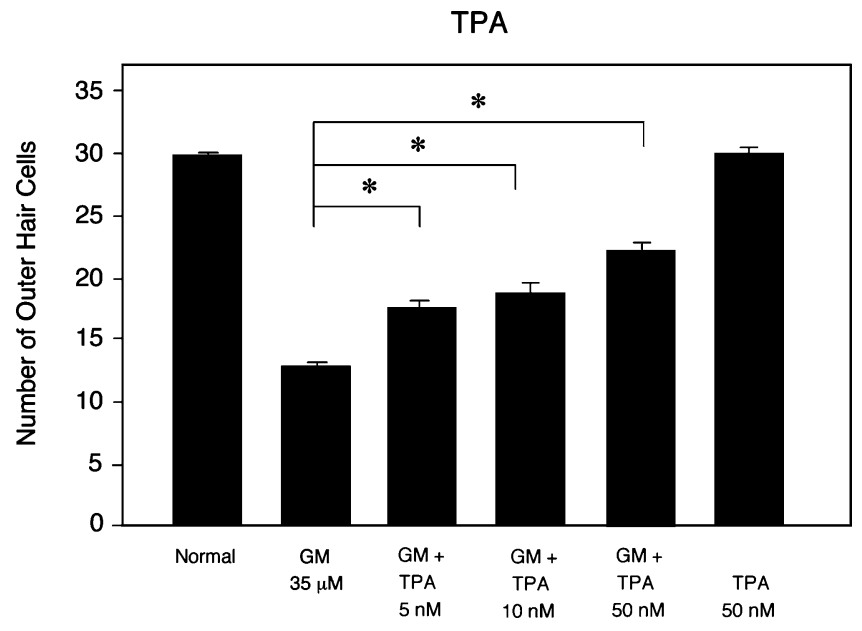

FIG. 5. Protective effect of TPA against gentamicin-induced hair cell loss. When TPA was combined with gentamicin, hair cell damage was significantly reduced at concentrations of 5,10 , or 50 $\mathrm{nM}$ when compared to gentamicin alone $(p<0.05)$. At $50 \mathrm{nM}$ TPA alone, no hair cell damage was observed. 


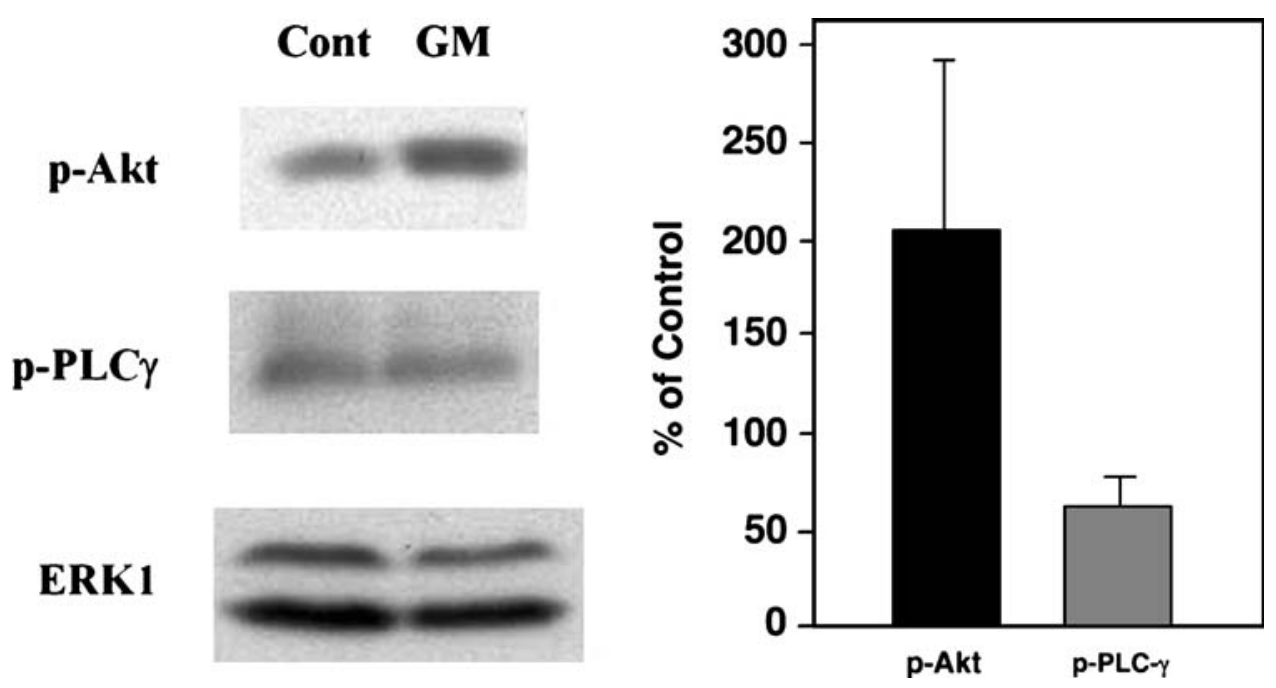

FIG. 6. Western blot analysis of $\mathrm{Akt}(\mathrm{PKB})$ and $\mathrm{PLC} \gamma$ phosphorylation in organ of Corti explants. Explants were treated with $50 \mu \mathrm{M}$ gentamicin (GM) for 6 h. Phospho-Akt and phospho-PLC $\gamma$ were detected by Western blot. Total Erk1 was used as an internal control. Phospho-protein levels were determined by densitometry and were normalized against Erk1. Gentamicin treated levels are expressed as \% of control values. Phospho Akt was significantly increased by gentamicin treatment $(p<0.05)$, whereas phospho-PLC $\gamma$ levels were not.

to determine whether the present results could be generalized to hair cells in situ.

The data of the present study provide several lines of evidence implicating the activation of a PI3K signaling pathway that promotes hair cell survival. We observed the activation of PI3K target, PKB/Akt, by using a Western blot analysis at $6 \mathrm{~h}$ after gentamicin treatment. Relative to a control protein, phospho-Akt increased approximately by $200 \%$. Treatment with the PI3K inhibitor, LY294002, combined with gentamicin wors-

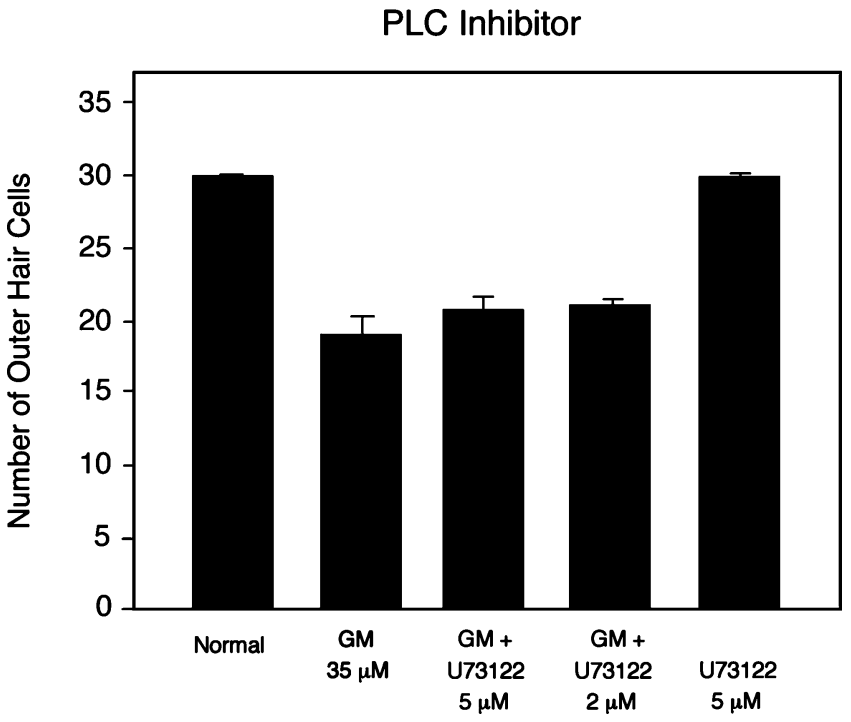

FIG. 7. Hair cell damage by gentamicin combined with the PLC inhibitor, U73122. U73122 (5,2 $2 \mathrm{M})$ combined with gentamicin had no significant effect on damage, compared to that seen with gentamicin alone $(p<0.05)$. ened hair cell loss. This indicates that PI3K plays a role in promoting hair cell survival, and supports the previous observations of Schacht et al. (1977) that implicate PI metabolism in ototoxicity. In addition, especially the PKC inhibitor (calphostin C) and, to a lesser extent, the $\mathrm{PKB} /$ Akt inhibitor (SH-6) combined with gentamicin enhanced hair cell death more than gentamicin alone. Finally, TPA, a PKC activator, was found to be protective against gentamicin-induced hair cell loss.

In contrast, when a PLC $\gamma$ inhibitor was used combined with gentamicin, there was no effect on hair cell loss. PLC $\gamma$ activation was not observed by Western blot after $6 \mathrm{~h}$ of gentamicin treatment. These data suggest that PKC activation pathway in hair cells is likely to be via PI3K rather than PLC $\gamma$ activation.

Taken together, our protein activation and inhibition data suggested that PI3K is involved in a hair cell survival pathway induced by gentamicin. PKC and PKB/Akt, common downstream targets of PI3K, are also involved although PKC may predominate. The downstream targets of PI3K signaling were not directly addressed in this study, and they can be complex. However, PKC is known to activate Mek/Erk signaling via Raf-1, leading to the transcription of genes involved in cell survival such as antiapoptotic members of the Bcl-2 family (e.g., Liu et al. 1999). PKB has been shown to act posttranslationally by phosphorylating, and thus inhibiting, the proapoptotic Bcl-2 protein, Bad (e.g., Yu et al. 2005) (Fig. 8). Thus these two arms of PI3K signaling may act via different and complementary mechanisms.

The mechanism of upstream activation of these signaling molecules is not clear. One possibility is the interaction of gentamicin and/or a metabolite with an 


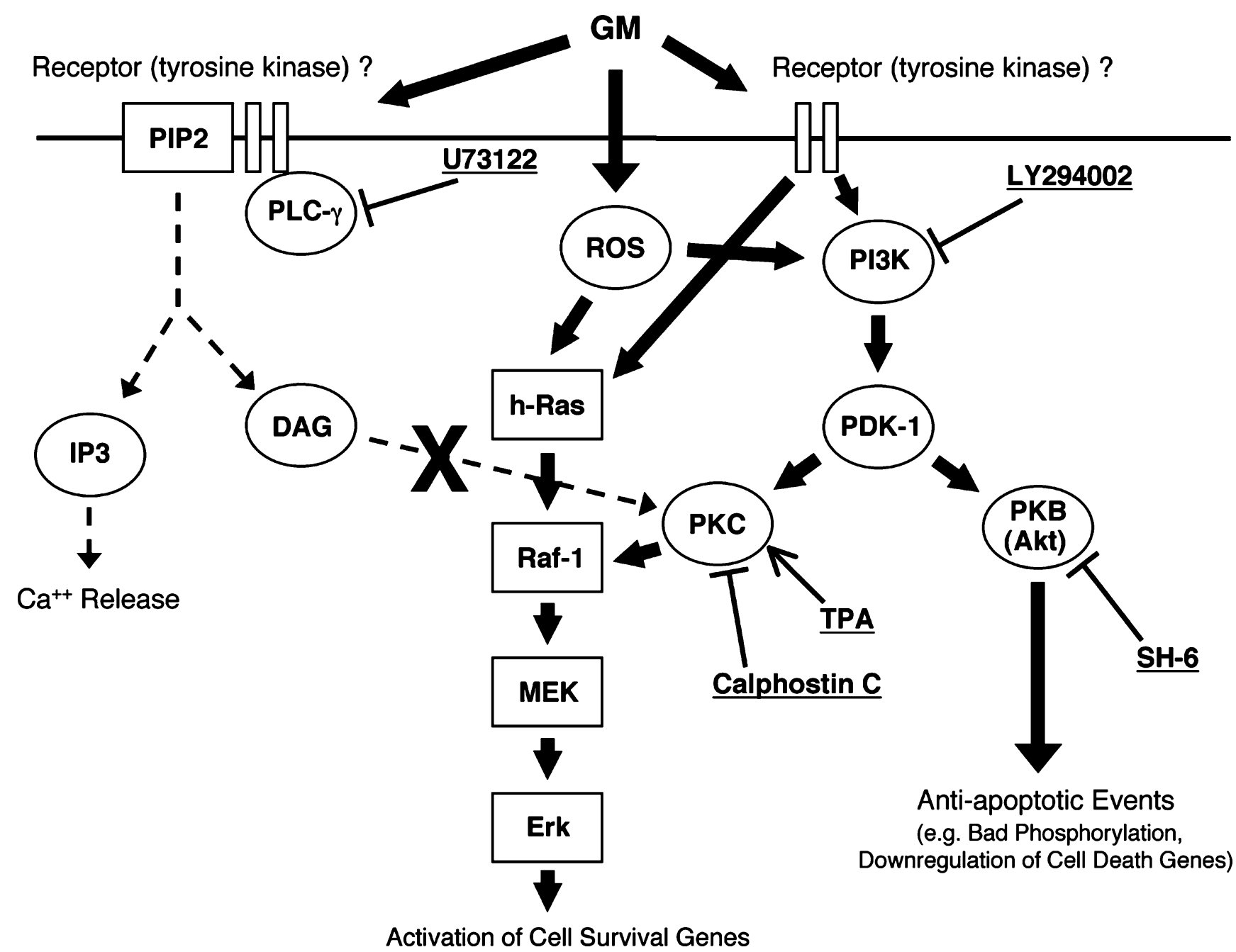

FIG. 8. Proposed survival pathway induced by gentamicin in the mammalian organ of Corti. PI3K activation of PKC and PKB leads to downstream enhancement of survival and inhibition of apoptosis. PLC $\gamma$ activation of PKC is not involved. Pathway components tested directly in this study are indicated in gray.

unknown cell surface receptor. Another alternative is the direct activation of intracellular signaling by ROS. ROS is well known to be related to gentamicin ototoxicity (e.g., Wu et al. 2002; McFadden et al. 2003). Intracellular gentamicin may chelate with iron and interact with phosphoinositides to produce ROS (Wu et al. 2002). ROS is reported to induce tyrosine phosphorylation of the p110 catalytic subunit of PI3K and to activate PKB/Akt through PI3K membrane recruitment (Qin and Chock 2003). Our findings are schematically summarized in Figure 8.

Our data, implicating PI3K in the hair cell response to gentamicin, support the observations of Schacht and his colleagues regarding the importance of PI metabolism in the process of aminoglycoside ototoxicity (e.g., Schacht et al. 1977; Willams et al. 1987). They also complement the many other recent studies that have documented signal transduction pathways leading to hair death due to a variety of stressors, including aminoglycosides (e.g., Pirvola et al. 2000; Bodmer et al. 2002a), cisplatin (e.g., Zhang et al. 2003; Wang et al. 2004), and noise exposure (e.g., Harris et al. 2005; Lang et al. 2006).

The recruitment of pathways that promote cellular survival by toxins that are known to produce cell death may not at first glance appear logical. However, the activation of parallel pathways leading to cell death on the one hand, and cell survival on the other is a common feature of responses to stress in many tissues (Wang et al. 2001; Salvesen 2002). In fact, processes leading to cell death are heavily regulated, with inhibitory points at multiple levels of pathways leading to apoptosis or necrosis. Survival pathways, by enhancing this limiting regulation, presumably allow cells to survive brief or sublethal exposures to stress with less damage. For example, growth factor exposure, long known to en- 
hance the survival of many cell types exposed to stress, has been shown to increase the expression of genes encoding antiapoptotic proteins such as Bcl-2 and IAP (e.g., Liu et al. 1999), or to influence function posttranslationally as in phosphorylation of Bad (e.g., Yu et al. 2005). Naturally, there are limitations to what protective pathways can accomplish, or cells would never succumb to toxins. When stress is prolonged or intense, it can tip the balance of cell signaling toward cell death. Once initiated, apoptosis and/or necrosis proceed rapidly to completion.

If the activation of survival pathways occurs in vivo, it might be possible to employ them clinically to protect hair cells from ototoxicity. Growth factors known to activate PI3K and H-Ras (GDNF, FGF) are one possibility. Such factors have been shown to protect hair cells from toxicity in vitro (Low et al. 1996; Kawamoto et al. 2003). Small molecule analogs of signaling molecules are another potential mechanism. The survival pathways identified in this and other studies may also protect hair cells against other forms of stress, such as noise- or ageinduced damage. Of course, there are many steps between in vitro observations and useful pharmacologic interventions that would need to be traversed.

\section{ACKNOWLEDGMENT}

This research was supported by NIH/NIDCD grant DC00139 and the Research Service of the Veterans Administration.

\section{REFERENCE}

Balendran A, Hare GR, Kieloch A, Williams MR, Alessi DR. Further evidence that 3-phosphoinositide-dependent protein kinase-1 (PDK1) is required for the stability and phosphorylation of protein kinase C (PKC) isoforms. FEBS Letts 484(3):217-223, 2000.

Barthel A, Klotz LO. Phosphoinositide 3-kinase signaling in the cellular response to oxidative stress. Biol. Chem. 386:207-216, 2005.

Battaglia A, Pak K, Brors D, Bodmer D, Frangos Ja, Ryan AF. Involvement of ras activation in toxic hair cell damage of the mammalian cochlea. Neuroscience 122(4):1025-1035, 2003.

Boatright KM, Salvesen GS. Caspase activation. Biochem. Soc. Symp. (70):233-242, 2003.

Bodmer D, Brors D, Pak K, Gloddek B, Ryan A. Rescue of auditory hair cells from aminoglycoside toxicity by Clostridium difficile toxin B, an inhibitor of the small GTPases Rho/Rac/Cdc42. Hear. Res. 172(1-2):81-86, 2002a.

Bodmer D, Gloddek B, Ryan AF, Huverstuhl J, Brors D. Inhibition of the c-Jun N-terminal kinase signaling pathway influences neurite outgrowth of spiral ganglion neurons in vitro. Laryngoscope 112(11):2057-2061, 2002b.

Bright R, Mochly-Rosen D. The role of protein kinase $\mathrm{C}$ in cerebral ischemic and reperfusion injury. Stroke 36:2781-2790, 2005.

Brunn GJ, Williams J, Sabers C, Wiederrecht G, LaWrence JC, Abraham RT. Direct inhibition of the signaling functions of the mammalian target of rapamycin by the phosphoinositide 3-kinase inhibitors, wortmannin and LY294002. EMBO 15:5256-5267, 1996.
Cai H, Smola U, Wixler V, Eisenmann-Tappe I, Diaz-Meco M, Moscat J, RAPP U, COOPER G. Role of diacylglycerol-regulated protein kinase $\mathrm{C}$ isotypes in growth factor activation of the Raf-1 protein kinase. Mol. Cell. Biol. 17(2):732-741, 1997.

Cantley LC. The phosphoinositide 3-kinase pathway. Science 296(5573):1655-1657, 2002.

Carpenter G, Ji Q. Phospholipase C-r as a signal-transducing element. Exp. Cell Res. 253:15-24, 1999.

Coling DE, Schacht J. Protein phosphorylation in the organ of Corti: differential regulation by second messengers between base and apex. Hear. Res. 57(1):113-120, 1991.

Crann Sa, Huang MY, McLaren JD, Schacht J. Formation of a toxic metabolite from gentamicin by a hepatic cytosolic fraction. Biochem. Pharmacol. 43(8):1835-1839, 1992.

da Rocha AB, Mans DR, Regner A, Schwartsmann G. Targeting protein kinase $\mathrm{C}$ : new therapeutic opportunities against highgrade malignant gliomas? Oncologist 7(1):17-33, 2002.

Emran MA, Rebbaa A, Mirkin BL. Doxorubicin resistant neuroblastoma cells secrete factors that activate AKT and attenuate cytotoxicity in drug-sensitive cells. Cancer Lett. 182(1):53-59, 2002.

Forge A, Li L. Apoptotic death of hair cells in mammalian vestibular sensory epithelia. Hear. Res. 139(1-2):97-115, 2000.

Franke TF, Hornik CP, Segev L, Shostak GA, Sugimoto C. PI3K/Akt and apoptosis: size matters. Oncogene 22(56):8983-8998, 2003.

Fukazawa R, Miller TA, Kuramochi Y, Frantz S, Kim YD, Marchionn MA, Kelly RA, SawYer DB. Neuregulin-1 protects ventricular myocytes from anthracycline-induced apoptosis via erbB4dependent activation of PI3-kinase/Akt. J. Mol. Cell Cardiol. 35(12):1473-1479, 2003.

Harris KC, Hu B, Hangauer D, Henderson D. Prevention of noiseinduced hearing loss with Src-PTK inhibitors. Hear. Res. 208 (1-2):14-25, 2005.

Huang MY, Schacht J. Formation of a cytotoxic metabolite from gentamicin by liver. Biochem. Pharmacol. 40(11):R11-R14, 1990.

Huang J, Mohammadi M, Rodrigues GA, Schlessinger J. Reduced activation of RAF-1 and MAP kinase by a fibroblast growth factor receptor mutant deficient in stimulation of phosphatidylinositol hydrolysis. J. Biol. Chem. 270(10):5065-5072, 1995.

Jin W, Lo T-M, LOH HH, Thayer SA. U73122 inhibits phospholipase C-dependent calcium mobilization in neuronal cells. Brain Res. 642(1-2):237-243, 1994.

Katterle Y, Brandt BH, Dowdy SF, Niggemann B, Zänker KS, Dittmar T. Antitumour effects of PLC-1-(SH2)2-TAT fusion proteins on EGFR/c-erbB-2-positive breast cancer cells. Br. J. Cancer 90(1): 230-235, 2004

Kawamoto K, Yagi M, Stover T, Kanzaki S, Raphael Y. Hearing and hair cells are protected by adenoviral gene therapy with TGFbeta1 and GDNF. Mol. Ther. 7(4):484-492, 2003.

Khwaja A. Apoptosis: Akt is more than just a Bad kinase. Nature 401(6748):33-34, 1999

Kobayashi E, Nakano H, Morimoto M, Tamaoki T Calphostin C. (UCN-1028C), a novel microbial compound, is a highly potent and specific inhibitor of protein kinase C. Biochem. Biophys. Res. Commun. 159(2):548-553, 1989.

Kolch W, Heidecker G, Kochs G, Hummel R, Vahidi H, Mischak H, Finkenzeller G, Marme D, Rapp UR. Protein kinase $\mathrm{C}$ alpha activates RAF-1 by direct phosphorylation. Nature 364(6434):249-252, 1993.

Kozikowski AP, Sun H, Brognard J, Dennis PA. Novel PI analogues selectively block activation of the pro-survival serine/threonine kinase Akt. JACS 125:1144-1145, 2003.

KUEMMERLE JF. IGF-I elicits growth of human intestinal smooth muscle cells by activation of PI3K, PDK-1, and p70S6 kinase. Am. J. Physiol.: Gasterointest. Liver Physiol. 284:411-422, 2003. 
Lang H, Schulte BA, Zhou D, Smythe N, Spicer SS, Schmiedt RA. Nuclear factor kappaB deficiency is associated with auditory nerve degeneration and increased noise-induced hearing loss. J. Neurosci. 26(13):3541-3550, 2006.

Leblanc P, L'Héritier A, Kordon C. Delta opiate receptors account for the castration-induced unmasking of gonadotropin-releasing hormone binding sites in the rat pituitary. Neuroendocrinology 68(6):386-394, 1998.

Liu YZ, Boxer LM, Latchman DS. Activation of the Bcl-2 promoter by nerve growth factor is mediated by the p $42 / \mathrm{p} 44$ MAPK cascade. Nucleic. Acids. Res. 15;27(10):2086-2090, 1999.

Low W, Dazert S, Baird A, RyAn AF. Basic fibroblast growth factor (FGF-2) protects rat cochlear hair cells in organotypical culture from aminoglycoside injury. J. Cell Physiol. 167(3):443-450, 1996.

McCubrey JA, May WS, Duronio V, Mufson A. Serine/threonine phosphorylation in cytokine signal transduction. Leukemia 14(1):9-21, 2000.

MaFadden SL, Ding D, Salvemini D, Salvi RJ. M40403, a superoxide dismutase mimetic, protects cochlear hair cells from gentamicin, but not cisplatin toxicity. Toxicol. Appl. Pharmacol. 186(1):46-54, 2003.

Montcouguiol M, Corwin JT. Intracellular signals that control cell proliferation in mammalian balance epithelia: key roles for phosphatidylinositol-3 kinase, mammalian target of rapamycin, and S6 kinases in preference to calcium, protein kinase $\mathrm{C}$, and mitogen-activated protein kinase. J. Neurosci. 21 (2):570-580, 2001.

Nishizuka Y. Studies and perspectives of protein kinase C. Science 233(4761):305-312, 1986.

Oliva JL, Griner EM, Kazanietz MG. PKC isozymes and diacylglycerol-regulated proteins as effectors of growth factor receptors. Growth Factors 23:245-252, 2005.

Ozaki I, Tani E, Ikemoto H, Kitagawa H, Fujikawa H. Activation of stress-activated protein kinase/c-Jun $\mathrm{NH}_{2}$-terminal kinase and p38 kinase in calphostin C-induced apoptosis requires caspase3-like proteases but is dispensable for cell death. J. Biol. Chem. 274(9):5310-5317, 1999.

Pirvola U, Xing-Qun L, Virkkala J, Saarma M, Murakata C, Camoratto AM, Walton KM, Ylikoski J. Rescue of hearing, auditory hair cells, and neurons by CEP-1347/KT7515, an inhibitor of c-Jun N-terminal kinase activation. J. Neurosci. 20(1):43-50, 2000.

QIN S, Сноск B. Implication of phosphatidylinositol 3-kinase membrane recruitment in hydrogen peroxide induced activation of PI3K and Akt. Biochemistry 42:2995-3003, 2003.

RAFF MC. Social controls on cell survival and cell death. Nature 356(6368):397-400, 1992.

Ramen LE, Cantley LC. The role of phosphoinositide 3-kinase lipid products in cell function. J. Biol. Chem. 274(13):8347-8350, 1999.

RichaRdSON GP, Russell IJ. Cochlear cultures as a model system for studying aminoglycoside induced ototoxicity. Hear. Res. 53:293-311, 1991.

SALVESEN GS. Caspases and apoptosis. Essays Biochem. 38:9-19, 2002.
Santagata S, Boggon tJ, Baird CL, Gomez CA, Zhao J, Shan WS, Myszka DG, Shapiro L. G-protein signaling through tubby proteins. Science 292(5524):2041-2050, 2001.

Schacht J, Lodhi S, Weiner ND. Effects of neomycin on polyphosphoinositides in inner ear tissues and monomolecular films. Adv. Exp. Med. Biol. 84:191-208, 1977.

Schonwasser DC, Marais RM, Marshall CJ, Parker PJ. Activation of the mitogen-activated protein kinase/extracellular signalregulated kinase pathway by conventional, novel, and atypical protein kinase C isotypes. Mol. Cell. Biol. 18(2):790-798, 1998.

Song G, Ouyang G, BaO S. The activation of Akt/PKB signaling pathway and cell survival. J. Cell. Mol. Med. 9:59-71, 2005.

TAKEUChI K, Iто F. Suppression of adriamycin-induced apoptosis by sustained activation of the phosphatidylinositol-3'-OH kinaseAkt pathway. J. Biol. Chem. 279(2):892-900, 2004.

Vlahos C, Matter W, Hui K, Brown R. A specific inhibitor of phosphatidylinositol 3-kinase, 2-(4- morpholinyl)-8-phenyl-4H-1benzopyran-4-one (LY294002). J. Biol. Chem. 269(7):5241-5248, 1994.

Wang C-Y, Mayo MW, Korneluk RG, Goeddel DV, Baldwin AS Jr. NF-B Antiapoptosis: Induction of TRAF1 and TRAF2 and cIAP1 and c-IAP2 to suppress caspase- 8 activation. Science 281(5383):1680-1683, 1998.

Wang X-T, McCullough KD, Wang X-J, Carpenter G, Holbrook NJ. Oxidative stress-induced phospholipase C-gamma 1 activation enhances cell survival. J. Biol. Chem. 276(30):28364-28371, 2001.

Wang J, Ladrech S, Pujol R, Brabet P, Van De Water TR, Puel Jl. Caspase inhibitors, but not c-Jun NH2-terminal kinase inhibitor treatment, prevent cisplatin-induced hearing loss. Cancer Res. 64(24):9217-9224, 2004.

Webb PR, Wang KQ, Scheel-Toellner D, Pongracz J, Salmon M. Regulation of neutrophil apoptosis: A role for protein kinase $\mathrm{C}$ and phosphatidylinositol-3-kinase. Apoptosis 5:451-458, 2000.

Willams SE, Zenner HP, Schacht, J. Three molecular steps of aminoglycoside ototoxicity demonstrated in outer hair cells. Hear. Res. 30:11-18, 1987.

Witte MC, Montcouguiol M, Corwin JT. Regeneration in avian hair cell epithelia: identification of intracellular signals required for S-phase entry. Eur. J. Neurosci. 14(5):829-838, 2001.

Wu WJ, Sha SH, Schacht J. Recent advances in understanding aminoglycoside ototoxicity and its prevention. Audiol. Neurootol. 7:171-174, 2002.

Ylikoski J, Xing-Qun L, Virkkala J, Pirvola U. Blockade of c-Jun N-terminal kinase pathway attenuates gentamicin-induced cochlear and vestibular hair cell death. Hear. Res. 166:33-43, 2002.

Yu F, Sugawara T, Maier CM, Hsieh LB, Chan PH. Akt/Bad signaling and motor neuron survival after spinal cord injury. Neurobiol. Dis. 20(2):491-499, 2005.

Zhang M, Liu W, Ding D, Salvi R. Pifithrin-alpha suppresses p53 and protects cochlear and vestibular hair cells from cisplatininduced apoptosis. Neuroscience 120(1):191-205, 2003. 